\title{
Exchange reactions of poly(arylene ether ketone) dithioketals with aliphatic diols: formation and deprotection of poly(arylene ether ketal)s
}

Article

Accepted Version

Manolakis, I., Cross, P. and Colquhoun, H. (2017) Exchange reactions of poly(arylene ether ketone) dithioketals with aliphatic diols: formation and deprotection of poly(arylene ether ketal)s. Macromolecules, 50 (24). pp. 9561-9568. ISSN 0024-9297 doi: https://doi.org/10.1021/acs.macromol.7b02203 Available at https://centaur.reading.ac.uk/73954/

It is advisable to refer to the publisher's version if you intend to cite from the work. See Guidance on citing.

To link to this article DOI: http://dx.doi.org/10.1021/acs.macromol.7b02203

Publisher: American Chemical Society

All outputs in CentAUR are protected by Intellectual Property Rights law, including copyright law. Copyright and IPR is retained by the creators or other copyright holders. Terms and conditions for use of this material are defined in the End User Agreement. 


\section{CentAUR}

Central Archive at the University of Reading

Reading's research outputs online 


\title{
Exchange reactions of poly(arylene ether ketone) dithioketals with aliphatic diols: formation and deprotection of poly(arylene ether ketal)s
}

\author{
Ioannis Manolakis ${ }^{\dagger \S}$, Paul Cross ${ }^{\star}$ and Howard M. Colquhoun ${ }^{\dagger *}$ \\ Department of Chemistry, University of Reading, Whiteknights, Reading, RG6 6AD, UK and \\ Cytec Aerospace Materials (Solvay Group), Wilton Centre, Redcar, Cleveland, TS10 4RF, UK \\ Corresponding author: h.m.colquhoun@rdg.ac.uk \\ ${ }^{\dagger}$ University of Reading \\ $¥$ Cytec Aerospace Materials \\ ${ }^{\S}$ Current address: $\quad$ Irish Composites Centre (IComp), School of Engineering, Bernal Institute, \\ University of Limerick, Limerick, Ireland
}

Short title: Exchange reactions of poly(arylene ether ketone) dithioketals with diols

ABSTRACT: The dithioketal derivatives of industrially important, semi-crystalline poly(arylene ether ketone)s undergo facile exchange with aliphatic diols in the presence of N-bromosuccinimide to give a range of novel poly(arylene ether ketal)s. These are amorphous and readily soluble in a wide range of organic solvents. Although generally stable under ambient conditions, they undergo rapid and quantitative hydrolysis in the presence of acids to regenerate the original polyketones. The poly(ether ketal)s reported here are not accessible from ketal-type monomers, nor can they be obtained by direct reaction of poly(ether ketone)s with aliphatic diols. The starting polyketones are essentially unchanged after sequential dithioketalization, dithioketalketal exchange, ketal hydrolysis, and re-dithioketalization. Poly(arylene ether ketal)s provide a new approach to the processing of poly(arylene ether ketone)s into carbon fiber composite materials. 


\section{Introduction}

The poly(arylene ether ketone)s represent a class of industrially important, semi-crystalline, high-performance thermoplastics (Chart 1). Since the commercial introduction of these materials in the $1970 \mathrm{~s},{ }^{1,2}$ their applications have expanded steadily as a result of an attractive combination of high mechanical strength and toughness, solvent resistance, thermo-oxidative stability and outstanding thermomechanical performance. These properties have led to wide-ranging applications, especially in automotive, biomedical and aerospace technologies. ${ }^{3,4}$ In particular, their use as thermoplastic matrices in structural carbon-fiber composites for aircraft production, both civil and military, is now growing significantly as a result of their high toughness relative to cross-linked, thermosetting matrices such as the epoxies and bis-maleimides. ${ }^{5}$
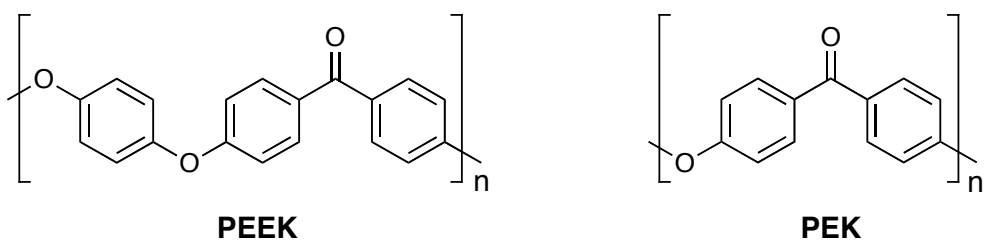<smiles>COc1ccc(C(=O)c2ccc(Oc3ccc(C(=O)c4ccc(C(C)(C)C)cc4)cc3)cc2)cc1</smiles>

PEKEKK<smiles>COc1ccc(C(=O)c2cccc(C(=O)c3ccc(C(C)(C)C)cc3)c2)cc1</smiles>
PEKK (family of 1,3/1,4-copolyketones)

Chart 1. Some industrially important poly(arylene ether ketone)s 
However, many of the properties of poly(arylene ether ketone)s which make them valuable in application can also cause problems in synthesis and processing. For example, their high levels of crystallinity and consequent insolubility in conventional solvents limit the methods by which they can be processed into composite materials. In addition, their high melt viscosities and the requirement for high processing temperatures $\left(\mathrm{ca} .400{ }^{\circ} \mathrm{C}\right.$ ) makes both fiber-impregnation and composite-fabrication challenging. These difficulties are overcome to some extent in current thermoplastic composite technologies by very careful control of polymer molecular weight and by the use of novel impregnation methodologies ${ }^{6,7}$ However, if it were possible to reversibly "protect" semi-crystalline poly(arylene ether ketone)s, turning them into more readily-processed amorphous materials that could subsequently be de-protected once fiber-impregnation had been achieved, then the application of poly(arylene ether ketone)s in composite applications might become much more straightforward. ${ }^{8}$

The idea of reversible chemical modification of poly(arylene ether ketone)s without compromising their final properties has been explored in the past. ${ }^{9-14}$ Amongst the first efforts was that of Kelsey et al., ${ }^{14}$ who synthesized the cyclic ethylene ketal of 4,4'dihydroxybenzophenone. This "protected" monomer underwent polycondensation with 4,4'difluorobenzophenone in DMAc or sulfolane, and the resulting poly(ether ketal ketone) proved amorphous and readily soluble in chlorinated and dipolar aprotic solvents. Hydrolysis of the ketal groups was achieved heterogeneously by reaction with dilute $\mathrm{H}_{2} \mathrm{SO}_{4}$ or $\mathrm{HCl}$ (working above $160{ }^{\circ} \mathrm{C}$ in an autoclave to achieve exhaustive deprotection) or homogeneously in concentrated sulfuric acid. An alternative protection strategy involved a ketimine-based monomer obtained by reaction of aniline with 4,4'-difluorobenzophenone, which was successfully condensed with hydroquinone in the presence of $\mathrm{K}_{2} \mathrm{CO}_{3}$, to afford a poly(ether ether ketimine) ${ }^{15,16}$ Subsequent 
hydrolysis was achieved using either methanesulfonic acid or $\mathrm{HCl}$, and light-scattering measurements showed that hydrolysis did not degrade the polymer backbone. In related work, Manolakis et al. showed that high-boiling aralkylamines such as 2,2-diphenylethylamine and 3,3diphenylpropylamine reacted quantitatively with high-MW PEEK at $270{ }^{\circ} \mathrm{C}$ in diphenyl sulfone to give soluble, amorphous poly(ether ketimine)s. ${ }^{17}$

With specific relevance to the present work, a further novel approach to fully-reversible derivatisation of poly(arylene ether ketone)s has been reported. ${ }^{18,19,20}$ The carbonyl groups were protected by reaction with dithiols such as 1,2-ethanedithiol and 1,3-propanedithiol under acidic conditions to give the corresponding cyclic dithioketals (e.g. Scheme 1). Reactions occurred essentially quantitatively, in dichloromethane or chloroform, in the presence of a strong protic acid (e.g. trifluoroacetic acid) to solubilize the ketone and a Lewis acid $\left(\mathrm{BF}_{3} \cdot \mathrm{Et}_{2} \mathrm{O}\right)$ to promote the reaction. The resulting poly(ether dithioketal)s were readily soluble in solvents such as dichloromethane, chloroform, and THF. Quantitative deprotection was achieved by heating the protected polymer in $\mathrm{CHCl}_{3}$ with t-butyl iodide and dimethylsulfoxide for 48 hours. ${ }^{19}$

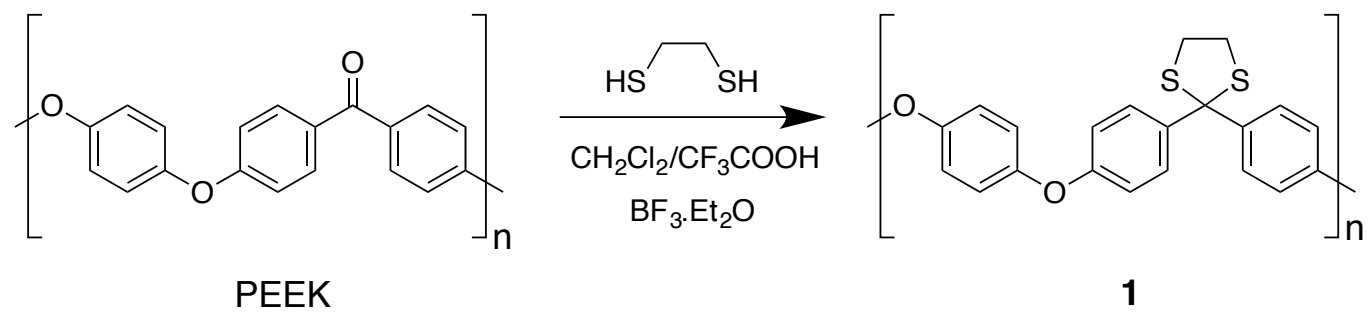

Scheme 1. Dithioketalization of PEEK ${ }^{19}$

The dithioketalization approach offers a general, non-degradative pathway for reversible chemical modification of any poly(arylene ether ketone). However, removal of the dithioketal group is generally slow and difficult (though achievable) ${ }^{19}$ and a derivative that is stable under processing conditions but more readily deprotected would be very desirable. In small-molecule 
chemistry, cyclic dithioketals are also difficult to hydrolyze but they do participate in exchange reactions, for example with ethane-1,2-diol or 2-mercaptoethanol in the presence of a catalyst such as mercury(II) chloride, yielding the corresponding 1,3-dioxolanes or 1,3-oxathiolanes..$^{21,22}$ Moreover, it has been reported that a slight stoichiometric excess of the halogenating agent $N$-bromosuccinimide (NBS) promotes very rapid interchange (a few minutes at room temperature) of 1,3-dithioketals with aliphatic diols, ${ }^{22}$ affording cyclic acetals of aromatic and aliphatic ketones in good yields (60-90\%). Even acyclic dimethylketals of small-molecule aldehydes and ketones have been obtained by reaction of cyclic dithioketals with methanol or ethanol in the presence of NBS. ${ }^{22}$ Although the detailed mechanism of the exchange reaction is unknown, the oxidising character of NBS (effectively a source of $\mathrm{Br}^{+}$) strongly suggests that the dithiol residue is activated towards replacement by oxidation/halogenation at sulfur. Certainly no thiol-type odours could be detected when working with this type of polymer system. 
<smiles>COc1ccc(Oc2ccc(C3(c4ccc(C)cc4)SCCS3)cc2)cc1</smiles>

1<smiles>COc1ccc(Oc2ccc(C3(c4ccc(C)cc4)SCCCS3)cc2)cc1</smiles>

2<smiles>COc1ccc(C2(c3ccc(C)cc3)SCCCS2)cc1</smiles>

3<smiles>COc1ccc(C2(c3ccc(C4(c5ccccc5)SCCCS4)cc3)SCCCS2)cc1</smiles><smiles>COc1ccc(C2(c3ccc(Oc4ccc(C5(c6ccc(C7(c8ccc(C)cc8)SCCCS7)cc6)SCCCS5)cc4)cc3)SCCCS2)cc1</smiles>

4<smiles>Oc1ccc(C2(c3cccc(C4(c5ccc(CCOc6ccccc6)cc5)SCCCS4)c3)SCCCS2)cc1</smiles>

5

Chart 2. Poly(ether dithioketal)s investigated in dithioketal-ketal exchange reactions

Here we describe successful applications of NBS-promoted dithioketal/ketal exchange reactions to high-MW polymers, using the previously-reported poly(ether dithioketal)s (Chart 2) as starting materials. These interchange reactions have allowed the synthesis of a wide variety of novel poly(ether ketal)s (Chart 3). Moreover we have found that PEEK-1,3-dioxolane, $\mathbf{6}$, can be hydrolyzed rapidly and quantitatively under mild conditions, regenerating PEEK that is identical in all measurable respects to the PEEK polymer from which the poly(ether ether dithioketal) was originally synthesized. 


\section{Results and Discussion}

\section{Reactions of PEEK dithioketals with ethane-1,2-diol}

Preliminary studies showed that prolonged reactions $(18-20 \mathrm{~h})$ of dithioketals of poly(ether ketone)s such as PEEK-1,3-dithiolane 1 with 1.4 equivalents of NBS per dithioketal group and a 4-fold molar excess of ethane-1,2-diol, in dichloromethane at room temperature, gave only fully hydrolyzed poly(ether ketone)s rather than the anticipated poly(ether ketal)s. However, by working at much shorter reaction times (5-10 min), PEEK-1,3-dioxolane derivatives could be isolated in high yield (Scheme 2).

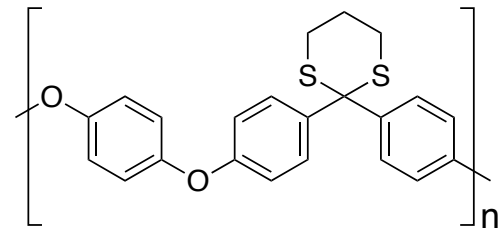

2

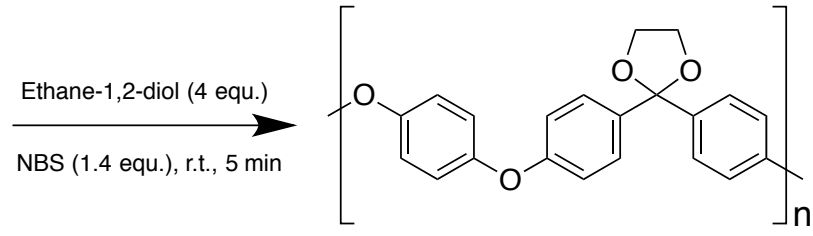

6

Scheme 2. Successful NBS-promoted PEEK-dithioketal/ketal exchange reaction.

Analysis of poly(ether ketal)s by ${ }^{1} \mathrm{H}$ NMR spectroscopy showed no detectable dithioketal residues, but deprotected ketonic units were present at levels of between 5 and 45 mole\%. Both PEEK-1,3-dithiolane (1) and PEEK-1,3-dithiane (2) successfully participated in this reaction, forming the same end-products. The ${ }^{1} \mathrm{H}-\mathrm{NMR}$ spectra of PEEK-1,3-dithiane (starting material 2) and PEEK-1,3-dioxolane (product 6 ) are shown in Figure 1. 


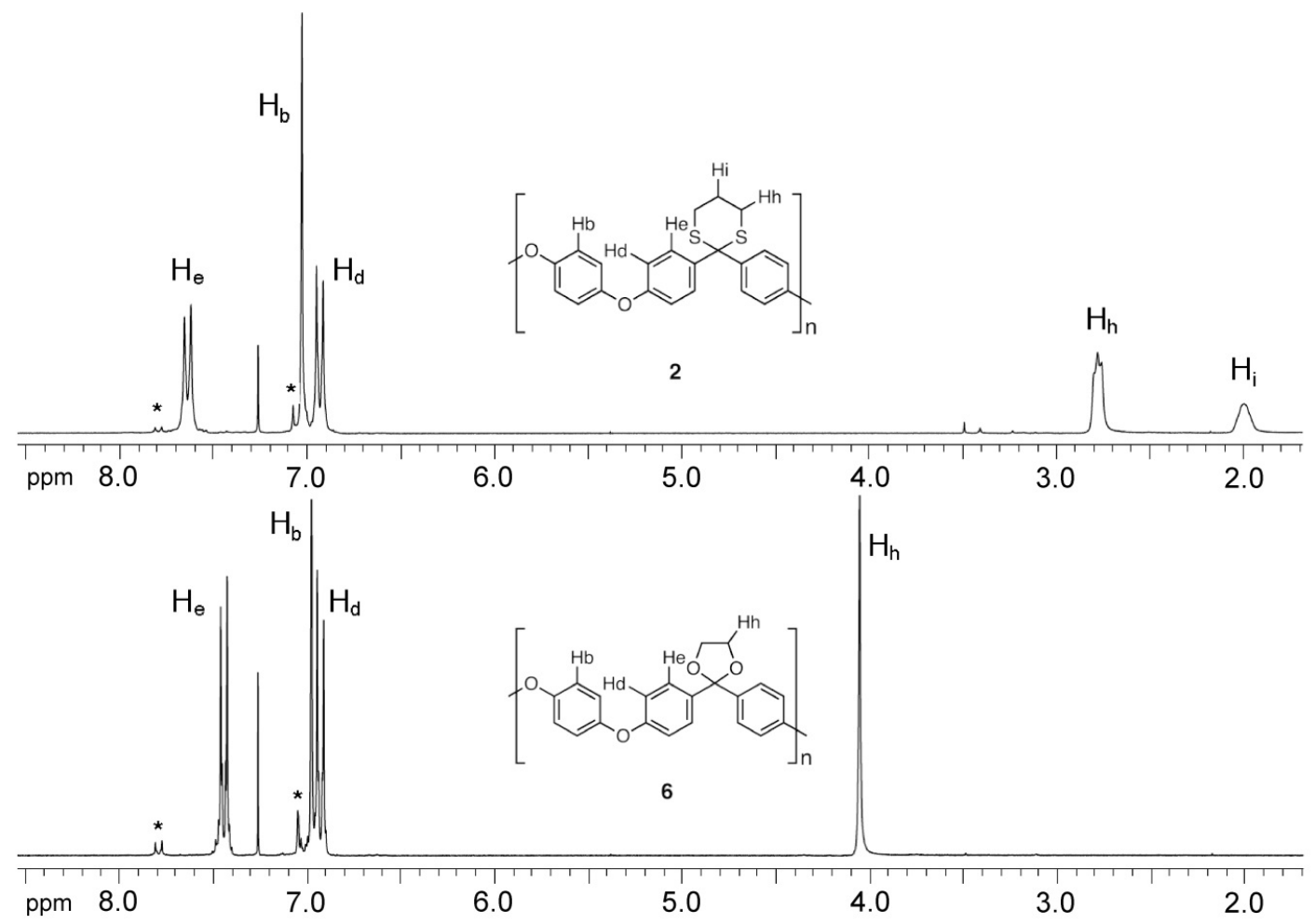

Figure 1. ${ }^{1} \mathrm{H}$ NMR spectra of PEEK-1,3-dithiane (2, above) and PEEK-1,3-dioxolane (6, below) in $\mathrm{CDCl}_{3}$. Asterisks indicate aromatic proton resonances associated with residual ketonic residues.

The starting PEEK-1,3-dithiane (2) contained 3\% mole of residual ketonic units. Resonances characteristic of these units appeared at approximately $7.8 \mathrm{ppm}\left(\mathrm{AA}^{\prime} \mathrm{XX}, 4 \mathrm{H}\right)$ and $7.1 \mathrm{ppm}(\mathrm{s}$, 4H) (Figure 1). The aliphatic protons of the dithiane ring resonated at 2.80-2.76 ppm (br, 4H, $\left.\mathrm{H}_{\mathrm{h}}\right)$ and $2.00 \mathrm{ppm}\left(\mathrm{br}, 2 \mathrm{H}, \mathrm{H}_{\mathrm{i}}\right)$. The absence of these latter resonances and the appearance of a singlet at $4.05 \mathrm{ppm}$, corresponding to four methylenic protons, indicate ketal exchange and formation of the 1,3-dioxolane ring. The final 1,3-dioxolane-based polymer, $\mathbf{6}$, formed from PEEK-1,3dithiane, 2, contained only 5 mole $\%$ of residual ketone: no resonances associated with residual NBS or its reaction products were detected. The ${ }^{13} \mathrm{C}-\mathrm{NMR}$ spectra (see SI) of polymers 2 and $\mathbf{6}$ confirmed formation of the 1,3-dioxolane ring. In $\mathbf{6}$, the chemical shift values for the aliphatic ring carbons at $65.3 \mathrm{ppm}$ and the protected carbonyl-carbon at $109.5 \mathrm{ppm}$ were in agreement 
with values for the poly(ether ketal-ketone) reported by Kelsey, ${ }^{14}$ as were values for the carbons in the aromatic region. Further characterisation data for poly(ether ketal) 6 are given in Table 1.

Table 1. Characterization data for dithioketal and ketal derivatives of PEEK

\begin{tabular}{|c|c|c|c|c|c|c|}
\hline Polymer & $\eta_{\text {inh }}$ & $M_{\mathrm{n}}(\mathrm{RI})$ & $M_{\mathrm{w}} / M_{\mathrm{n}}$ & $M_{\mathrm{n}}(\mathrm{LS})$ & $M_{\mathrm{w}} / M_{\mathrm{n}}$ & $T_{\mathrm{g}}$ onset \\
\hline PEEK-1,3-dithiolane & 0.38 & 21.2 & 2.45 & 14.5 & 2.90 & 157 \\
\hline PEEK-1,3-dithiane & 0.48 & 24.0 & 2.73 & 18.1 & 3.15 & 179 \\
\hline PEEK-1,3-dioxolane & 0.39 & 26.6 & 2.25 & 16.1 & 2.49 & 139 \\
\hline
\end{tabular}

a) In chloroform at $25{ }^{\circ} \mathrm{C}$; ${ }^{\text {b) }} \mathrm{By} \mathrm{GPC}$ in chloroform at $35^{\circ} \mathrm{C}$; ${ }^{\text {c) }} \mathrm{By} \mathrm{DSC}$

The 1,3-dithiane derivative $\mathbf{2}$, should have a slightly higher molar mass than the derived 1,3dioxolane polymer $\mathbf{6}$, provided that the exchange reaction occurred without chain degradation: the GPC and inherent viscosity and light scattering measurements indeed confirmed this. A small proportion of a high molecular weight component was also revealed by light-scattering analysis (see SI) and this was observed consistently for polymers $\mathbf{1 , 2}$ and $\mathbf{6}$, confirming that the polymer backbone remained intact during the exchange reaction. The PEEK-1,3-dioxolane derivative 6 was soluble in both chloroform and dichloromethane and also in THF, DMF and DMAc, but it only swelled in NMP and was insoluble in methanol. In general terms, the ketone content of the exchanged polymers increased with increasing reaction time beyond ca. $5 \mathrm{~min}$. As the ketone content increased, solubility was retained up to a critical percentage (ca. $45 \%$ mole of ketonic groups), above which insoluble polymer rapidly crystallized from solution. It was established that with a 5 min reaction time, polyketals having $80-85 \%$ of ketal groups could be consistently obtained. Further evidence for the high-yielding nature of the NBS-promoted, dithioketal-toketal exchange was provided by elemental analysis (See SI). No trace of sulfur in the PEEK-1,3- 
dioxolane product $\mathbf{6}$ could be detected, and calculated and experimental analyses for the two polymers were in very good agreement.<smiles>COc1ccc(Oc2ccc(C3(c4ccc(C(C)(C)C)cc4)OCCO3)cc2)cc1</smiles>

6<smiles>COc1ccc(Oc2ccc(C3(c4ccc(C)cc4)OCC(C)O3)cc2)cc1</smiles>

8<smiles>COc1ccc(C2(c3ccc(C)cc3)OCCO2)cc1</smiles>

10

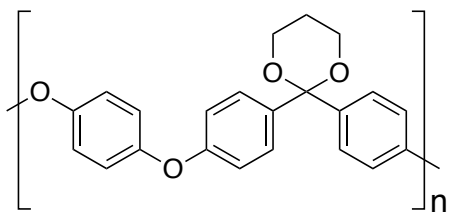

7

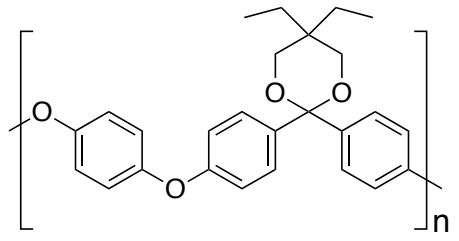

9<smiles>COc1ccc(C2(c3ccc(C)cc3)OCC(C)O2)cc1</smiles>

11<smiles>COc1ccc(C2(c3ccc(C)cc3)OCCCO2)cc1</smiles>

12<smiles>COc1ccc(C2(c3ccc(Oc4ccc(C5(c6ccc(C7(c8ccc(C)cc8)OCCO7)cc6)OCCO5)cc4)cc3)OCCO2)cc1</smiles>

13

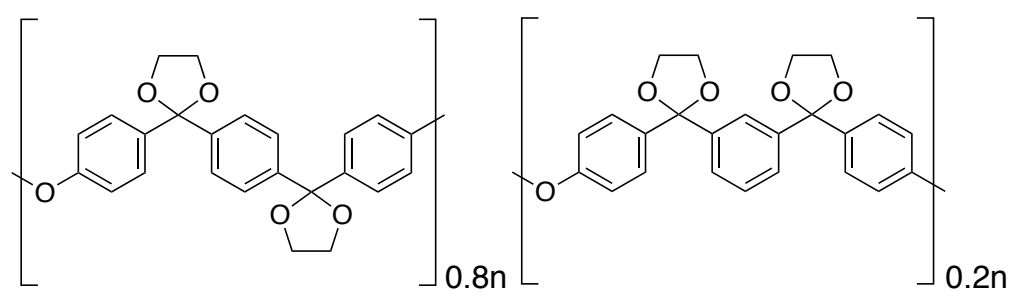

14

Chart 3. Poly(ether ketal)s obtained by dithioketal/ketal exchange reactions. All the poly(ether ketal)s shown were found to contain a proportion of deprotected ketone units (Figure 1 and SI). 


\section{Reactions of PEEK dithioketals with other diols and alcohols}

Two parameters were found to be critical for a successful exchange reaction, namely the solubility of the diol in dichloromethane (preferred reaction solvent) and the hydrolytic stability of the resulting ketal. Dithioketals of PEEK underwent successful exchange with 1,3propanediol, 1,2-propanediol and 2,2-diethyl-1,3-propanediol (Scheme 3) under the conditions optimized for ethane-1,2-diol. However, reactions with 2-methylene-1,3-propanediol and cis-1,2cyclohexanediol led to only hydrolysis and formation of PEEK, as did attempts to obtain acyclic poly(ether ketal)s using simple alcohols such as ethanol or methanol. The dithioketal derivatives of poly(arylene ether ketone)s investigated in this work are shown in Chart 2, and the poly(ether ketal)s obtained from them by NBS-promoted exchange are shown in Chart 3. Poly(ether ketal)s 7, 8 and 9 (Scheme 3) were analyzed by ${ }^{1} \mathrm{H}$ and ${ }^{13} \mathrm{C}$ NMR spectroscopy. These appear to be more prone to hydrolysis than PEEK-1,3-dioxolane 6, as their ketone levels were quite high (see SI).

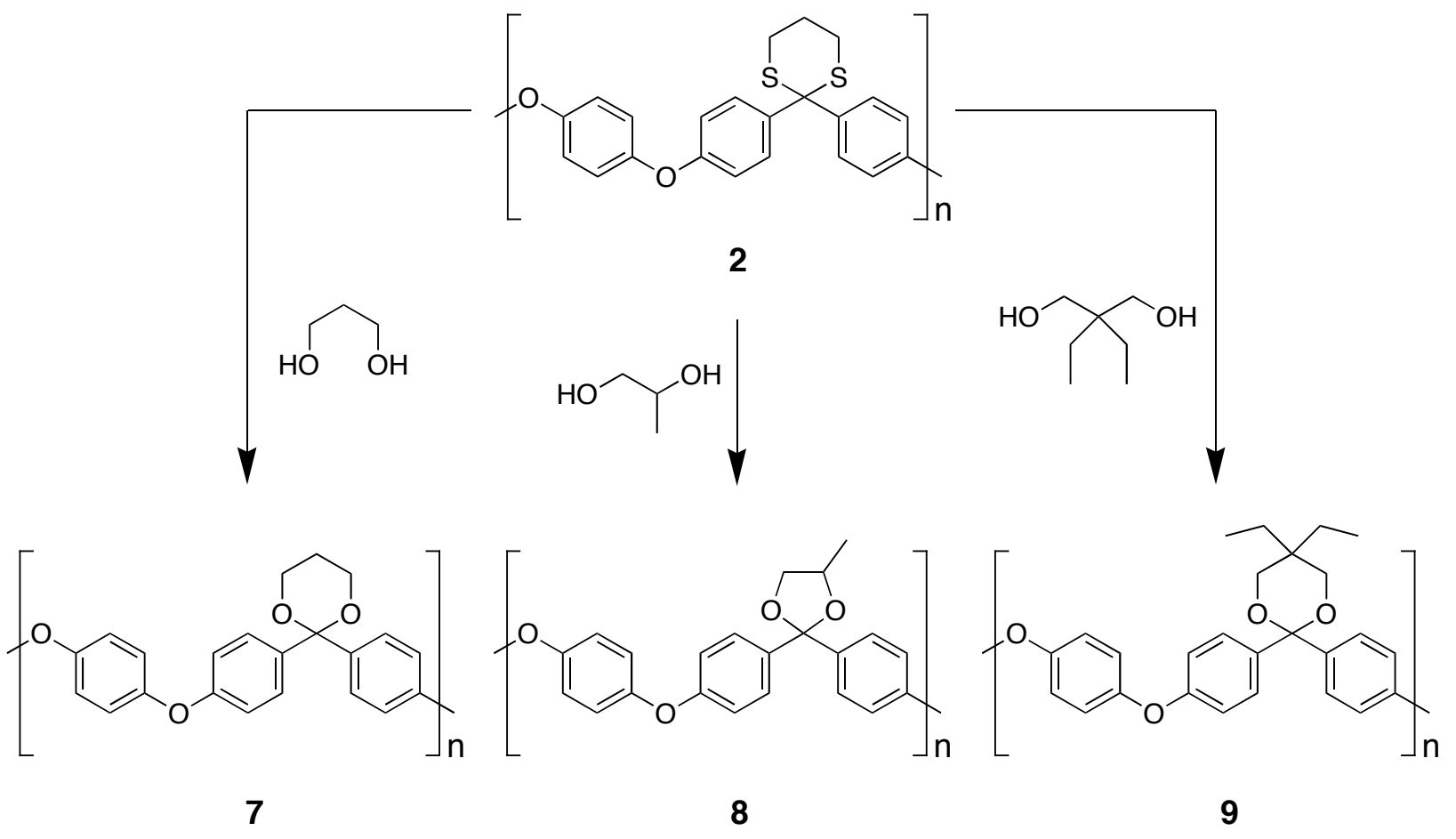

Scheme 3. Exchange reactions of PEEK-1,3-dithiane with various diols 
It was found that PEEK-1,3-dioxane 7 hydrolyzed rapidly in air simply on redissolving it in $\mathrm{CHCl}_{3}$, and so it proved impracticable to obtain GPC or inherent viscosity data for this polymer. The use of 2,2-diethyl-1,3-propanediol has been reported to afford small-molecule ketals that are significantly more resistant to hydrolytic cleavage than the corresponding 1,3-dioxolanes. ${ }^{23}$ In the present work, reaction of PEEK-1,3-dithiane 2 with 2,2-diethyl-1,3-propanediol was found to give a polyketal 9 containing only $65 \%$ of ketal groups, but the isolated polymer (unlike its unsubstituted counterpart 7) was indeed sufficiently air-stable to allow GPC and viscometry data to be obtained (see SI).

\section{Exchange reactions of poly(ether dithioketal)s from other poly(arylene ether ketone)s}

To investigate the general applicability of the NBS-promoted ketal exchange reaction, poly(ether dithioketals) derived from the semi-crystalline poly(ether ketone)s PEK, PEKEKK and PEKK (Charts 1 and 2) were next studied. The resulting poly(ether ketal)s (Chart 3) were generally obtained in high yield, and with similar levels of residual ketone groups (7-24\%) to those seen in the corresponding PEEK-based systems (see SI), even though PEKEKK-1,3-dithiane merely swelled, rather than dissolved, in dichloromethane.

\section{Deprotection of PEEK-1,3-dioxolane - homogeneous hydrolysis}

In order for dithioketal/ketal interchange to be exploited in a possible solution-impregnation approach to composite materials, hydrolysis of the poly(ether ketals) must be rapid and quantitative and must proceed without any negative impact on the properties of the final matrix polyketone. Hydrolysis of PEEK-1,3-dioxolane 6, the most stable of the PEEK-based ketals obtained in this work, was therefore next investigated. Previous reports of heterogeneous hydrolysis of a PEK-1,3-dioxolane copolymer (50\% ketone, 50\% dioxolane), together with 
cleavage under homogeneous conditions in concentrated sulfuric acid, were given by Kelsey et $a l .{ }^{10}$ In the present work, PEEK-1,3-dioxolane $\mathbf{6}$ was dissolved in dichloromethane or chloroform at room temperature and concentrated aqueous $\mathrm{HCl}(37 \%)$ or $100 \%$ trifluoroacetic acid (TFA) was then added (Scheme 4). With TFA, the resulting PEEK remained in solution and was recovered by precipitation in methanol, but with $\mathrm{HCl}$, PEEK crystallized out after 20-30 minutes because $37 \% \mathrm{HCl}_{\mathrm{aq}}$ is not a sufficiently strong acid to retain the polyketone in solution. The structures of the deprotected PEEK samples were confirmed by ${ }^{1} \mathrm{H}-\mathrm{NMR}$ spectroscopy, and their thermal properties agreed with normal PEEK values. Characterisation data for the deprotected polymers (and their re-protected dithiane derivatives) are given in the SI.

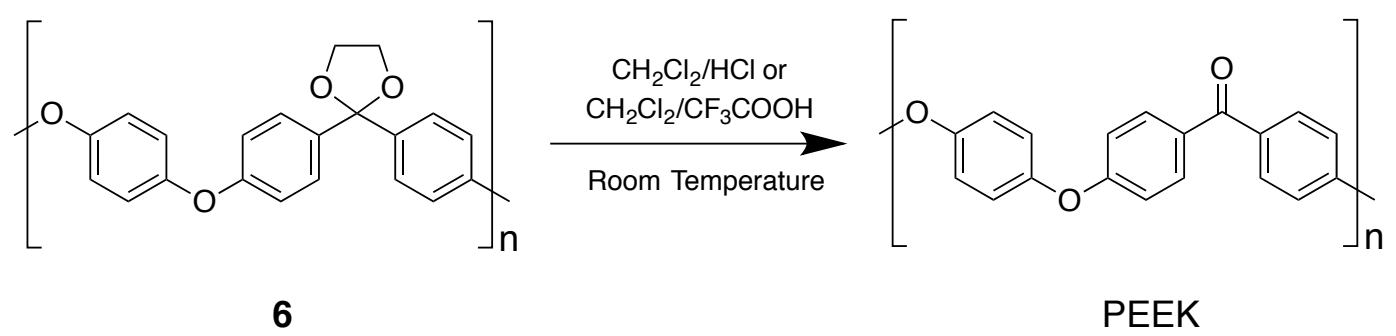

Scheme 4. Hydrolysis of PEEK-1,3-dioxolane (6)

The PEEK samples obtained from both deprotection protocols were re-derivatized with 1,2ethanedithiol and the resulting poly(ether dithioketal)s were compared. The two protected polymers had almost identical viscosities and molecular weight averages (see SI) and their GPC traces were virtually superimposable. Finally, the original PEEK starting material was derivatized with 1,3-propanedithiol, then exchanged with ethylene glycol to give $\mathbf{6}$, which was deprotected with trifluoroacetic acid to give PEEK, which was finally re-protected with 1,3propanedithiol. The properties of the starting and final PEEK-1,3-dithiane are listed in the SI and their GPC profiles are compared in Figure 2. Comparisons with the results in Table 2 confirm 
that neither the protection/deprotection nor the homogeneous ketal-exchange reactions of PEEK result in any detectable chain degradation. The same conclusion was reached for hydrolysis of PEEK-1,3-dioxolane in concentrated $\mathrm{HCl}$ : full details are given in the Supporting Information.

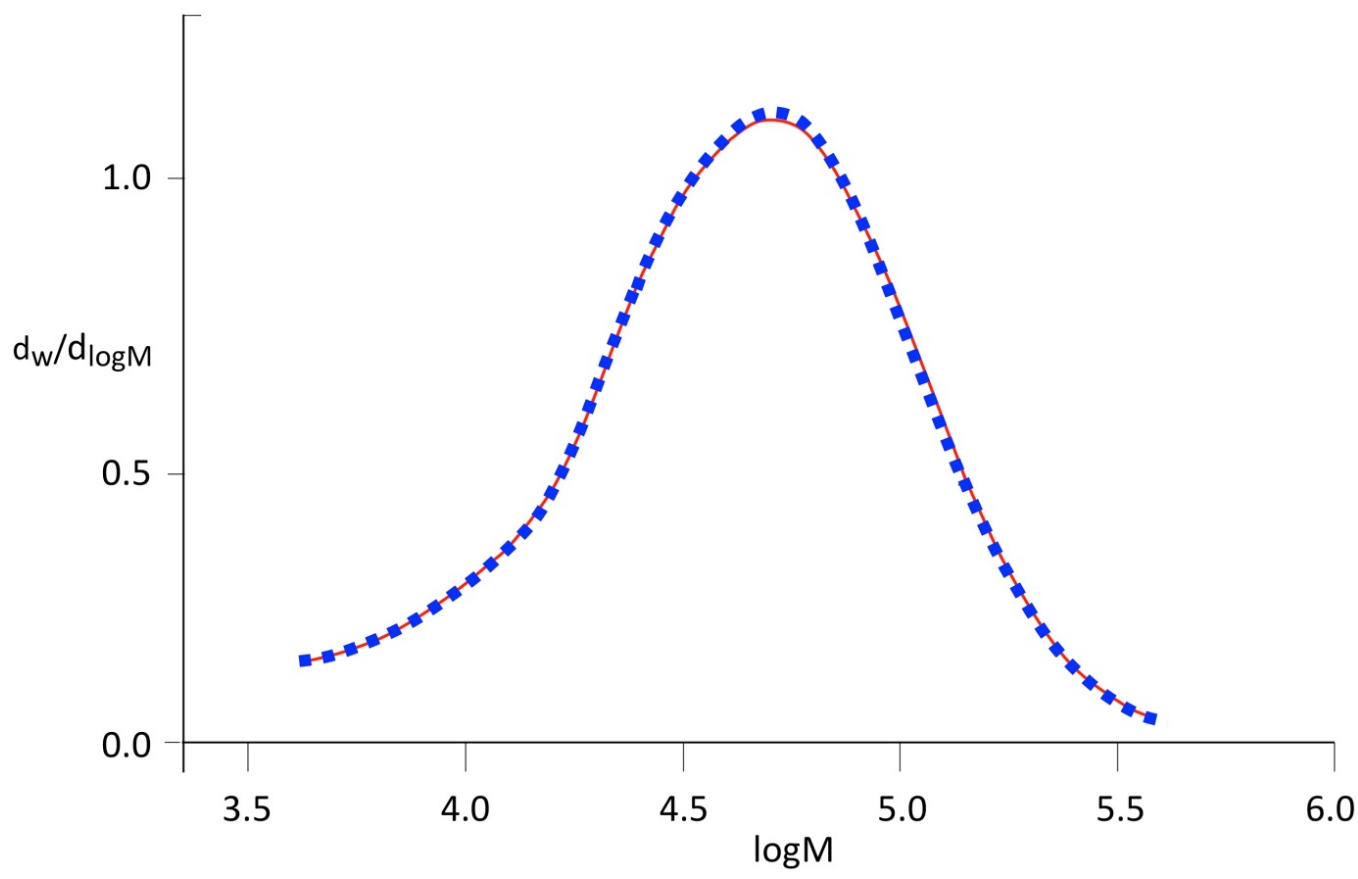

Figure 2. Gel permeation chromatograms of PEEK-1,3-dithiane 2, before and after dithioketal-ketal exchange. The blue dotted trace represents the starting polymer and the red trace represents polymer recovered after (i) dithioketal-ketal exchange of $\mathbf{2}$ to form polymer 6, (ii) hydrolysis of $\mathbf{6}$ to PEEK, and finally (iii) re-protection of the PEEK to give PEEK-1,3-dithiane 2. See SI for numerical data.

\section{Application of dithioketal/ketal exchange chemistry to PEEK composite processing}

Having demonstrated complete reversibility of the reaction sequence from $\mathbf{1}$ or $\mathbf{2}$ to $\mathbf{6}$ and thence to PEEK, we next carried out a preliminary investigation of this chemistry as applied to solutionimpregnation of carbon fiber (CF) with the poly(ether ether ketal) 6 and subsequent in-situ hydrolysis of the matrix to PEEK. First, a carbon fiber bundle was immersed in a 5\% solution of poly(ether ether ketal) 6 in chloroform, and was then drained and allowed to dry in air. 
Table 2. Characterisation of PEEK samples (and their re-protected 1,3-dithiolane derivatives) formed by homogeneous hydrolysis of PEEK-1,3-dioxolane (6)

\begin{tabular}{|c|c|c|c|c|c|c|c|c|}
\hline \multicolumn{2}{|c|}{$\begin{array}{l}\text { Hydrolysis conditions } \\
\text { for poly(ether ketal) } 6\end{array}$} & \multicolumn{3}{|c|}{ PEEK as formed } & \multicolumn{2}{|c|}{$\begin{array}{l}\text { Product (1) after } \\
\text { ethane-1,2-dithiol }^{\mathrm{a}}\end{array}$} & \multicolumn{2}{|c|}{ re-protection with } \\
\hline & & $\begin{array}{l}T_{\mathrm{g}}\left({ }^{\circ} \mathrm{C}\right) \\
\text { Onset }^{\mathrm{b}}\end{array}$ & $\begin{array}{l}T_{\mathrm{m}} \\
\left({ }^{\circ} \mathrm{C}\right)^{\mathrm{b}}\end{array}$ & $\eta_{\text {inh }}\left(\mathrm{dL} \mathrm{g}^{-1}\right)^{\mathrm{c}}$ & $\begin{array}{l}M_{\mathrm{n}}(\mathrm{RI}) \\
(\mathrm{kDa})^{\mathrm{d}}\end{array}$ & $\begin{array}{l}M_{\mathrm{w}} / M_{\mathrm{n}} \\
(\mathrm{RI})^{\mathrm{d}}\end{array}$ & $\begin{array}{l}T_{\mathrm{g}}\left({ }^{\circ} \mathrm{C}\right) \\
\text { Onset }^{\mathrm{a}}\end{array}$ & $\begin{array}{l}\eta_{\text {inh }} \\
\left(\mathrm{dL} \mathrm{g} \mathrm{g}^{-1}\right)^{\mathrm{d}}\end{array}$ \\
\hline Entry 1 & $\begin{array}{l}\mathrm{DCM} / \mathrm{HCl}_{\mathrm{aq}} \\
5: 1 \mathrm{v} / \mathrm{v}\end{array}$ & 146 & 337 & 0.72 & 25.1 & 2.17 & 165 & 0.30 \\
\hline Entry 2 & $\begin{array}{l}\text { DCM/TFA } \\
20: 1 \mathrm{v} / \mathrm{v}\end{array}$ & 147 & 333 & 0.67 & 25.0 & 2.16 & 162 & 0.31 \\
\hline
\end{tabular}

a $98-99 \%$ conversion. ${ }^{\mathrm{b}}$ By DSC. ${ }^{\mathrm{b}}$ In $98 \% \mathrm{H}_{2} \mathrm{SO}_{4}$ at $25{ }^{\circ} \mathrm{C} .{ }^{\mathrm{c}}$ By GPC in chloroform at $35{ }^{\circ} \mathrm{C} .{ }^{\mathrm{d}}$ In chloroform at $25^{\circ} \mathrm{C}$.

Analysis of the individual coated fibers by SEM showed a reasonably even coating and suggested very good adhesion of the polymer to the fiber (See SI). Next, a woven carbon fiber fabric was soaked in a $13.2 \mathrm{wt} \%$ chloroform solution of $\mathbf{6}$ (containing $85 \%$ ketal units by ${ }^{1} \mathrm{H}-$ NMR spectroscopic analysis) for $5 \mathrm{~h}$ and then allowed to dry at ambient temperature for $48 \mathrm{~h}$, to give a composite containing 44 vol\% of polymer 6. Scanning electron microscopy again showed good surface-wetting and adhesion between the polymer and the fiber, and DSC indicated that the matrix polymer was chemically unchanged after impregnation.

Samples of the poly(ether ether ketal) 6 pre-preg were then consolidated by compression moulding at high temperature $\left(370{ }^{\circ} \mathrm{C}\right)$ and pressure $(30$ bar) to give coupons of a laminate 0.3 $\mathrm{mm}$ in thickness, which were again characterized by DSC and IR microcopy (see SI, Figure S5). These analyses showed no evidence of matrix decomposition. Refluxing the dip-coated and compression-moulded specimens in concentrated aqueous $\mathrm{HCl}$ for several hours resulted in 
complete conversion of the amorphous poly(ether ether ketal) matrix to crystalline PEEK, with the matrix polymer changing visibly from transparent, amorphous 6 to white, semi-crystalline PEEK (Figure 3, inset b), without delamination from the fiber. Slight shrinkage of the dip-coated composite sample occurred during hydrolysis, but there was no visible shrinkage of the compression-moulded specimen.

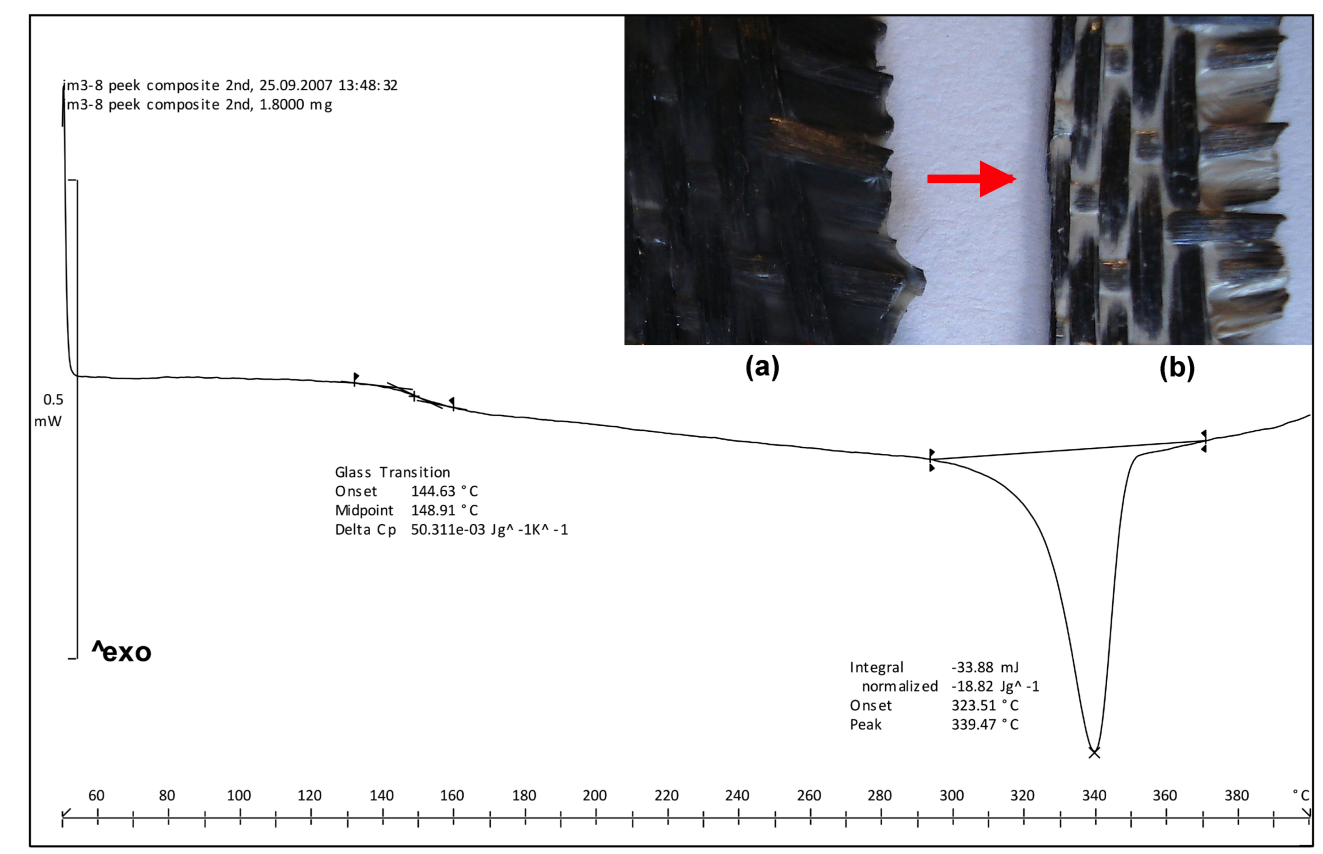

Figure 3. DSC thermogram of a carbon-fiber fabric impregnated with amorphous poly(ether ether ketal) 6 (inset a) which has then been hydrolyzed with conc. $\mathrm{HCl}$ to give a PEEK-carbon fiber composite (inset b). The melting point $\left(339^{\circ} \mathrm{C}\right)$ and $\operatorname{Tg}_{\text {onset }}\left(145^{\circ} \mathrm{C}\right)$ are fully consistent with literature values for PEEK.

An X-ray diffractogram of the hydrolyzed pre-preg (Figure 4) confirmed that the sample comprized a crystalline PEEK matrix reinforced with graphitic carbon fiber. Analysis of the hydrolyzed laminate by DSC and IR spectroscopy showed the same result for consolidated material. All the evidence thus indicates that hydrolysis of the amorphous matrix polymer $\mathbf{6}$, 
giving crystalline PEEK, may be achieved without disruption of the matrix-fiber interface, in both unconsolidated pre-preg and in thin sections of hot-pressed composite.

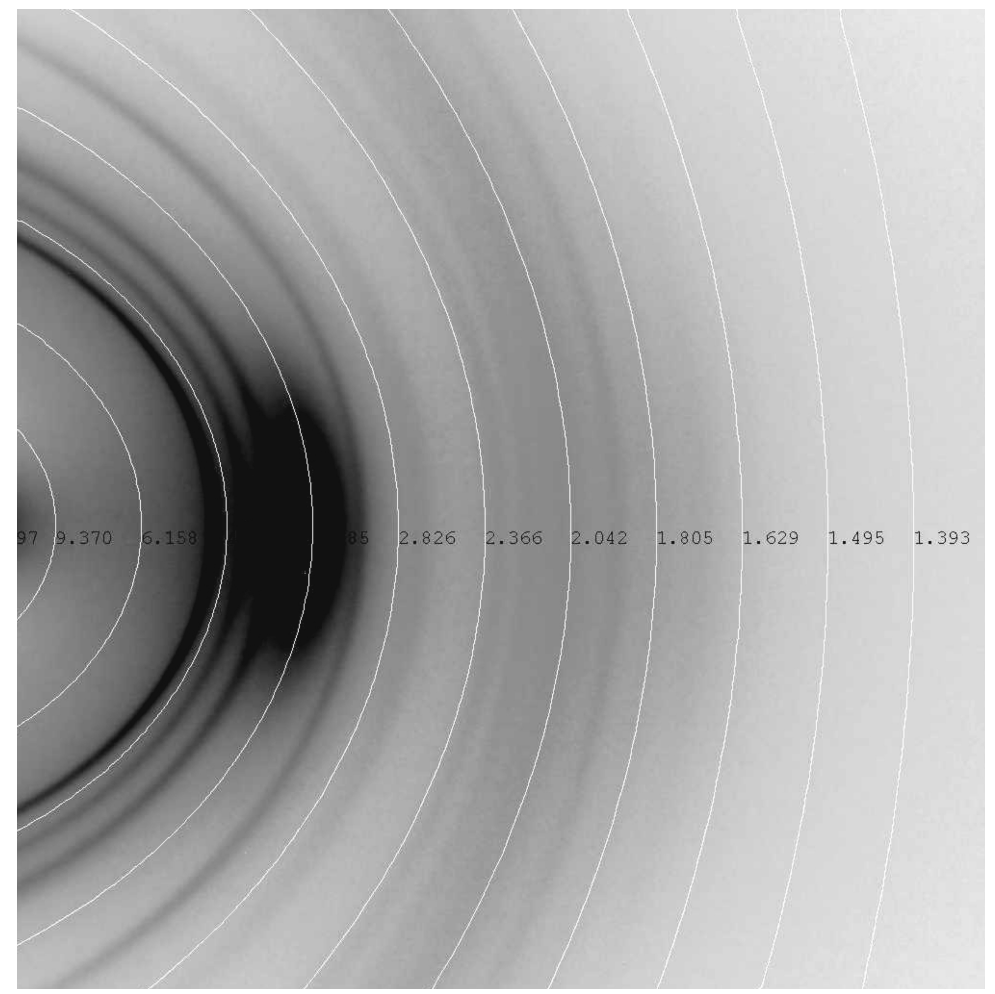

Figure 4. X-ray diffraction pattern of PEEK/carbon fiber composite formed by hydrolysis of PEEK-1,3dioxolane/carbon fiber pre-preg. A thermal treatment $\left(60 \mathrm{~min}\right.$ at $400{ }^{\circ} \mathrm{C}$, followed by $60 \mathrm{~min}$ at $320{ }^{\circ} \mathrm{C}$ and finally cooling to room temperature at $10{ }^{\circ} \mathrm{C} \mathrm{min}^{-1}$ ) was applied to the XRD specimen to maximize the crystallinity of the PEEK matrix before analysis. ${ }^{24-26}$ The carbon fiber was oriented vertically in the beam. The very strong equatorial spot-reflection arises from the oriented carbon fiber (graphite 200 reflection), and the diffraction rings are fully consistent with known $d$-spacings for PEEK. ${ }^{27}$

\section{Experimental Section}

Materials. Starting materials and solvents were obtained from Fisher UK and used as received unless stated otherwise. Samples of composite-grade polymers (PEEK and PEKK) were provided 
by Cytec Aerospace Materials. Other polyketones (PEK and PEKEKK) were provided as research samples by ICI plc.

Synthesis of PEEK-1,3-dithiolane, 1. A sample of PEEK (0.577 g, $2.0 \mathrm{mmol})$ was dissolved in a mixture of dichloromethane $(30 \mathrm{~mL})$ and trifluoroacetic acid $(3 \mathrm{~mL})$ with vigorous stirring under nitrogen. A cloudy yellow solution was formed. The system was purged with nitrogen for approximately $30 \mathrm{~min}$ and 1,2-ethanedithiol $(0.565 \mathrm{~g}, 6 \mathrm{mmol})$ was then added, followed by boron trifluoride diethyl etherate $(0.284 \mathrm{~g}, 2.0 \mathrm{mmol})$. A color change to dark red was observed and the solution slowly became completely clear. After $24 \mathrm{~h}$ the reaction mixture was poured into methanol $(60 \mathrm{~mL})$, giving a white precipitate which was filtered off, extracted with methanol, filtered off again and then dried at room temperature overnight. The product was recovered as a white powder $(0.705 \mathrm{~g}, 97 \%$ yield for PEEK-1,3-dithiolane, $\mathbf{1})$.

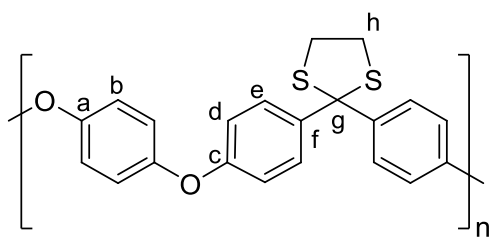

IR (film from chloroform) $v_{\max } / \mathrm{cm}^{-1}: 3064$ (-C-HAr), 3018 (C-H), 1593 (-C=C-), 1496 (-C=C-), 1214 (-C-O-C-), 1166 (-C-O-C-); ${ }^{1} \mathrm{H}-\mathrm{NMR}(250 \mathrm{MHz}, \mathrm{CDCl}): \delta_{\mathrm{H}}(\mathrm{ppm})=7.59-7.53(4 \mathrm{H}$, AA'XX', $\left.\mathrm{H}_{\mathrm{e}}\right), 6.99$ (4H, s, $\left.\mathrm{H}_{\mathrm{b}}\right), 6.89-6.84\left(4 \mathrm{H}, \mathrm{AA}^{\prime} \mathrm{XX}\right.$ ', $\left.\mathrm{H}_{\mathrm{d}}\right), 3.40\left(4 \mathrm{H}, \mathrm{s}, \mathrm{H}_{\mathrm{h}}\right) ; 13 \mathrm{C}-\mathrm{NMR}(62.5$ $\left.\mathrm{MHz}, \mathrm{CDCl}_{3}\right): \delta_{\mathrm{c}}(\mathrm{ppm})=157.4\left(\mathrm{C}_{\mathrm{a}}\right), 152.8\left(\mathrm{C}_{\mathrm{c}}\right), 139.3\left(\mathrm{C}_{\mathrm{f}}\right), 130.2\left(\mathrm{C}_{\mathrm{e}}\right), 121.2\left(\mathrm{C}_{\mathrm{b}}\right), 117.6\left(\mathrm{C}_{\mathrm{d}}\right)$, $76.5\left(\mathrm{C}_{\mathrm{g}}\right), 40.6\left(\mathrm{C}_{\mathrm{h}}\right) ; \eta_{\text {inh }}\left(\mathrm{CHCl}_{3}\right)=0.38 \mathrm{dL} \mathrm{g} \mathrm{g}^{-1} ; \mathrm{T}_{\mathrm{g}}$ (onset) $=157^{\circ} \mathrm{C}$; GPC (RI, $\left.\mathrm{CHCl}_{3}\right): \mathrm{M}_{\mathrm{n}}=$ $21.2, \mathrm{M}_{\mathrm{w}}=52.0 \mathrm{kDa} ; \mathrm{GPC}\left(\mathrm{LS}, \mathrm{CHCl}_{3}\right): \mathrm{M}_{\mathrm{n}}=14.5, \mathrm{M}_{\mathrm{w}}=42.0 \mathrm{kDa}$.

The synthesis of PEEK-1,3-dithiane 2 was carried out in an analogous manner (see SI). 
General procedure for NBS-promoted poly(dithioketal/ketal) exchange reactions. Synthesis of PEEK-1,3-dioxolane 6. PEEK-1,3-dithiane (2, $0.095 \mathrm{~g}, 0.25 \mathrm{mmol})$ was dissolved in dichloromethane $(15 \mathrm{~mL})$, and 1,2-ethanediol $(0.062 \mathrm{~g}, 1.00 \mathrm{mmol})$ was added followed by NBS (0.062 $\mathrm{g}, 0.35 \mathrm{mmol})$. A color change from pale yellow to purple was observed. After $5 \mathrm{~min}$, the reaction mixture was poured into methanol $(50 \mathrm{~mL})$ giving a white precipitate. The latter was filtered off, extracted with methanol, filtered off again and dried at room temperature overnight. Poly(ether ketal) 6 was obtained as a white powder ( $0.081 \mathrm{~g}, 98 \%$ yield).

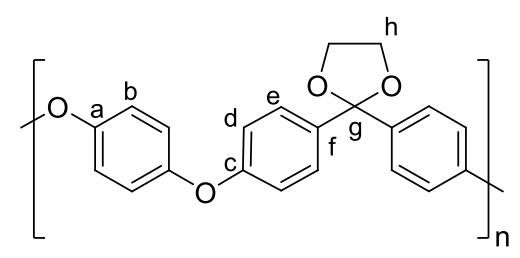

6

IR (film from $\mathrm{CHCl}_{3}$ ) $\mathrm{v}_{\max } / \mathrm{cm}^{-1}: 2988$ (-C-H-), 2900 (-C-H-), 1606 (-C-C-), 1495 (-C-C-), 1224 (C-O-C-), 1166 (-C-O-C-); ${ }^{1} \mathrm{H}-\mathrm{NMR}\left(250 \mathrm{MHz}, \mathrm{CDCl}_{3}\right): \delta_{\mathrm{H}}(\mathrm{ppm})=7.48-7.40\left(4 \mathrm{H}, \mathrm{AA}^{\prime} \mathrm{XX}^{\prime}\right.$, $\left.\mathrm{H}_{\mathrm{e}}\right), 6.97\left(4 \mathrm{H}, \mathrm{s}, \mathrm{H}_{\mathrm{b}}\right), 6.95-6.89\left(4 \mathrm{H}, \mathrm{AA}^{\prime} \mathrm{XX}, \mathrm{H}_{\mathrm{d}}\right), 4.05\left(4 \mathrm{H}, \mathrm{s}, \mathrm{H}_{\mathrm{h}}\right) ;{ }^{13} \mathrm{C}-\mathrm{NMR}(62.5 \mathrm{MHz}$, $\left.\mathrm{CDCl}_{3}\right): \delta_{\mathrm{c}}(\mathrm{ppm})=158.1\left(\mathrm{C}_{\mathrm{a}}\right), 152.9\left(\mathrm{C}_{\mathrm{c}}\right), 137.0\left(\mathrm{C}_{\mathrm{f}}\right), 128.2\left(\mathrm{C}_{\mathrm{e}}\right), 121.1\left(\mathrm{C}_{\mathrm{b}}\right), 118.0\left(\mathrm{C}_{\mathrm{d}}\right), 109.5$

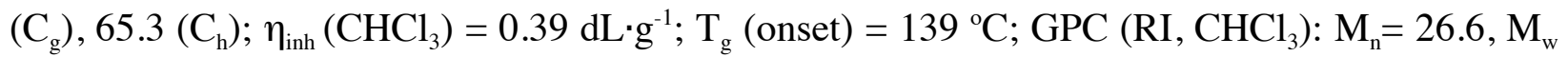
$=59.8 \mathrm{kDa}$; GPC (LS, $\left.\mathrm{CHCl}_{3}\right): \mathrm{M}_{\mathrm{n}}=16.1, \mathrm{M}_{\mathrm{w}}=40.1 \mathrm{kDa}$; Elemental analysis for $\mathrm{C}_{21} \mathrm{H}_{16} \mathrm{O}_{4}$ : Calculated: C 75.89, H 4.85\%; Found: C 75.85, H 4.78\%; S was below the detection limit $(<0.1 \%)$. 


\section{Conclusions}

A novel family of cyclic ketal derivatives of aromatic poly(ether ketone)s has been synthesized via an NBS-promoted exchange reaction between dithioketal-protected polymers and a range of aliphatic diols. These poly(ether ketal)s are not accessible from ketal-type monomers, nor can they be obtained by direct reaction of poly(ether ketone)s with aliphatic diols. Poly(ether ketal)s isolated from NBS-promoted exchange chemistry are shown to contain up to $95 \%$ of ketal groups (in the case of PEEK-1,3-dioxolane), with no residual dithioketal groups remaining in the polymers. It was further shown that PEEK-1,3-dioxolane can be easily and quantitatively deprotected by acid hydrolysis under both homogeneous and heterogeneous conditions, regenerating PEEK itself. Analysis by NMR, DSC, viscometry and GPC confirmed that the polymers obtained after dithioketal/ketal exchange and hydrolytic deprotection were essentially identical with the starting poly(ether ketone)s, indicating that neither of these reactions result in cleavage of the polymer backbone. This novel chemistry is applicable to all poly(ether ketone)s that are currently of industrial significance, and we have shown that the dithioketal/ketal exchange reaction has significant potential in the development of new processing methodologies for thermoplastic composites.

\section{Supporting Information.}

Materials and instrumentation. Synthesis of poly(ether dithoketal)s. General procedure for NBSpromoted poly(dithioketal/ketal) exchange reactions. Characterisation data for PEEK-1,3dioxolane (6) obtained from NBS-promoted reaction of PEEK-dithiane (2) with ethane-1,2-diol. Carbon fiber composite data. Characterisation data for poly(ether ketal)s. Deprotection of poly(ether ether ketal) 6. References to Supporting Information. 


\section{Author information}

\section{Corresponding author:}

* Email h.m.colquhoun@rdg.ac.uk.

\section{ORCID}

Howard M. Colquhoun: 0000-0002-3725-4085

\section{Notes:}

The authors declare no competing financial interest.

\section{Acknowledgments}

We thank Cytec Engineered Materials (now Cytec Solvay Group), the University of Reading, and the Engineering and Physical Sciences Research Council of the UK for support of this work through a PhD studentship to IM. 


\section{References}

(1) (a) Dahl, K. J. Polyketones and Methods Therefor. US Patent, US 3,953,400, 1976, to Raychem. (b) Glover, L. C.; Magay, D. Stilan 1000 - A Versatile High Performance Polymer for Hostile Environments, Tech. Papers - Soc. Plast. Eng. 1976, 22, 148-149.

(2) (a) Rose, J. B.; Staniland, P. A. Thermoplastic Aromatic Polyetherketones. US Patent, US 4,320,224, 1982, to ICI. (b) J. B. Rose, Discovery and Development of the "Victrex" Polyaryletherketone PEEK. In High Performance Polymers: Their Origin and Development; Seymour, R. B.; Kirshenbaum, G. S., Eds.; Elsevier, New York, 1986.

(3) (a) Shekar, R. I.; Kotresh, T. M.; Rao, P. M. D.; Kumar, K. Properties of high modulus PEEK yarns for aerospace applications. J. Appl. Polym. Sci. 2009, 112, 2497-2510. (b) Liang, Q.; Wu, X. Research Status of Carbon Fiber-reinforced PEEK Composites. Adv. Mater. Res. 2014, 834-836, 225-228.

(4) Panayotov, I. V.; Orti, V.; Cuisinier, F.; Yachouh, J. Polyetheretherketone (PEEK) for Medical Applications. J. Mater. Sci., Mater.Med. 2016, 27, 118.

(5) (a) Cantwell, W. J.; Davies, P. The Short-Term Properties of Carbon Fiber PEEK Composites. Adv. Thermoplast. Compos. 1993, 173-191. (b) Veasey, D.; Hsu, T; Gomez, E. D. Next Generation High-Performance Carbon Fiber Thermoplastic Composites Based on Polyaryletherketones. J. Appl. Polym. Sci. 2017, 134, 44441.

(6) Cogswell, F. N.; Measuria, U. Reinforced Composite Structures. European Patent, EP $150,931, \mathbf{1 9 9 0}$, to ICI.

(7) Texier, A.; Davist, R. M.; Lyon, K. R.; Gungor, A.; McGrath, J. E.; Marand, H.; Riffle, J. S. Fabrication of PEEK/Carbon Fiber Composites by Aqueous Suspension Prepregging. Polymer 1993, 34, 896-906.

(8) Pandya, A.; Yang, J.; Gibson, H.W. A new polyketone synthesis involving nucleophilic substitution via carbanions derived from bis( $\alpha$-aminonitrile)s. 1. Semicrystalline poly(arylene ketone sulfone)s. Macromolecules, 1994, 27, 1367-1375. 
(9) (a) Gibson, H. W.; Guilani, B. Polymers from Reissert compounds 6. Synthesis of poly(heteroarylene ether ketones) containing 1,4-isoquinolinediyl units, Polymer Commun. 1991, 32, 324-328.

(10) Yang, J.; Gibson, H. W. A new polyketone synthesis involving nucleophilic substitution via carbanions derived from bis(a-aminonitrile)s. 2. Wholly aromatic polyketones without ether linkages. Macromolecules 1997, 30, 5629-5633.

(11) Gibson, H. W.; Dotson, D. L. Wholly aromatic polymeric ketones from bis(aaminonitrile)s via soluble poly(bisaminonitrile)s. Polymer 1998, 39, 6483-6487;

(12) Yang, J.; Tyberg, C. S.; Gibson, H. W. A polyketone synthesis involving nucleophilic substitution via carbanions derived from bis(a-aminonitriles. 4. Aromatic poly(ether ketone)s. Macromolecules 1999, 32, 8259-8268.

(13) Yang, J.; Gibson, H. W. A polyketone synthesis involving nucleophilic substitution via carbanions derived from bis(a-aminonitrile)s. 5. A new, well controlled route to 'long' bisphenol and activated aromatic dihalide monomers. Macromolecules 1999, 32, 87408746.

(14) Kelsey, D. R.; Robeson L. M.; Clendinning R. A.; Blackwell, C. S. "Defect-Free", Crystalline Aromatic Poly(ether ketone)s: A Synthetic Strategy Based on Acetal Monomers. Macromolecules 1987, 20, 1204-1212.

(15) Mohanty, D. K.; Lowery, R. C.; Lyle, G. D.; McGrath, J. E. Ketimine Modifications as a Route to Novel Amorphous and Derived Semicrystalline Poly(arylene ether ketone) Homo- and Copolymers. Int. SAMPE Symp. 1987, 32, 408-419.

(16) Roovers J.; Cooney, J.D.; Toporowski, P. M. Synthesis and characterization of narrow molecular-weight distribution fractions of poly(aryl ether ether ketone). Macromolecules, 1990, 23, 1611-1618.

(17) Manolakis, I.; Cross, P.; Colquhoun, H. M. Direct Iminization of PEEK. Macromolecules, 2011, 44, 7864-7867. 
(18) Colquhoun, H. M.; Drew, M. G. B.; Hodge, P.; Paoloni, F. P. V.; McGrail, P. T. Dithioacetalisation of PEEK: A General Technique for the Solubilisation and Characterisation of Semi-Crystalline Aromatic Polyketones. Chem. Commun. 2007, 32, $3365-3367$.

(19) Colquhoun, H. M.; Hodge, P.; Paoloni, F. P. V.; McGrail, P. T.; Cross, P. Reversible, Nondegradative Conversion of Crystalline Aromatic Poly(ether ketone)s into OrganoSoluble Poly(ether dithioketal)s. Macromolecules, 2009, 42, 1955-1963.

(20) Cross, P. M.; McGrail, P. T; Colquhoun, H. M.; Hodge, P.; Manolakis, I.; Paoloni, F. P. V. Thioacetalisation of Poly(arylene ether ketone)s. UK Patent, GB 2,449,750, 2008, to Cytec.

(21) Corey, E. J.; Andersen, N. H.; Carlson, R. M.; Paust, J.; Vedejs, E.; Vlattas, I.; Winter, R. E. K. Total Synthesis of Prostaglandins. Synthesis of the Pure $d l-\mathrm{E}_{1},-\mathrm{F}_{\mathrm{la}},-\mathrm{F}_{\mathrm{l}^{\mathrm{\beta}}}-\mathrm{A}_{1}$ and $-\mathrm{B}_{1}$ Hormones. J. Am. Chem. Soc. 1968, 90, 3245-3246.

(22) Karimi, B.; Seradj, H.; Maleki, J. Highly Efficient and Chemoselective Interchange of 1,3-Oxathioacetals and Dithioacetals to Acetals Promoted by $\mathrm{N}$-Halosuccinimide. Tetrahedron 2002, 58, 4513-4516.

(23) Newman, M. S.; Harper, R. J. Kinetic and Equilibrium Studies of Cyclic Ketal Formation and Hydrolysis. J. Am. Chem. Soc. 1958, 80, 6350-6355.

(24) Saiello, S.; Kenny, J.; Nicolais, L. Interface Morphology of Carbon Fiber/PEEK Composites. J. Mat. Sci. 1990, 25, 3493-3496.

(25) Waddon, A. J.; Hill, M. J.; Keller, A.; Blundell, D. J. On the Crystal Texture of Linear Polyaryls (PEEK, PEK and PPS). J. Mat. Sci. 1987, 22, 1773-1784.

(26) Blundell, D. J.; Crick, R. A.; Fife, B.; Peacock J.; Keller A.; Waddon, A. Spherulitic Morphology of the Matrix of Thermoplastic PEEK/Carbon Fiber Aromatic Polymer Composites. J. Mat. Sci. 1989, 24, 2057-2064.

(27) Dawson, P. C.; Blundell, D. J. X-ray data for poly(arylene ether ketones). Polymer, 1980, $577-578$. 
For Table of Contents Use Only

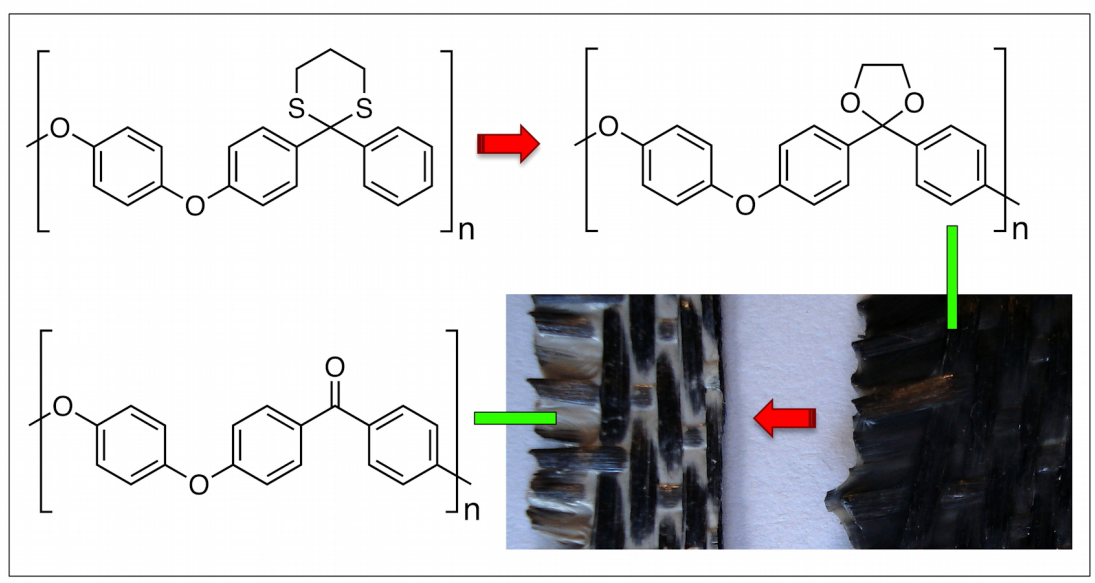

\section{Exchange reactions of poly(arylene ether ketone) dithioketals with aliphatic diols: formation and deprotection of poly(arylene ether ketal)s}

Ioannis Manolakis ${ }^{\dagger}$, Paul Cross ${ }^{\dagger}$ and Howard M. Colquhoun ${ }^{\dagger *}$

Department of Chemistry, University of Reading, Whiteknights, Reading, RG6 6AD, UK and Cytec Aerospace Materials (Solvay Group), Wilton Centre, Redcar, Cleveland, TS10 4RF, UK 